\title{
Efisiensi Motor Sinkron Linier dengan Magnet Permanen Sebagai Penggerak KRL Terbaru
}

\author{
Sofitri Rahayu$^{1}$; Yogi Baskoro \\ ${ }^{1}$ Sekolah Tinggi Teknik PLN \\ ${ }^{1}$ sofitri@sttpln.ac.id
}

\begin{abstract}
The latest electric train at this time, has begun to be widely used linear synchronous motors with permanent magnets as driving locomotives. This permanent magnet has the same function as a conventional synchronous motor which is to produce a magnetic field so that the motor can move linearly.This linear synchronous motor does not have a gear (gear) and axis, but the mechanical motion of this linear motor is synchronous with the magnetic field running. This running magnetic field is produced by the entanglement of the three phases and the arrangement of magnetic poles $U$, $S, U, S$. Because the motor is linear synchronous is a high-speed motor, the mechanical speed is the same as the speed of the magnetic field running. So that this motor is capable of producing large thrust compared to the use of conventional motors (DC motors and induction motors) to drive electric rail trains. If the conventional synchronous motor uses a frequency of $50 \mathrm{~Hz}$, then the linear high speed synchronous motor uses a frequency of 5-50 Hz in changing its speed and this research the efficiency, electromagnetic power (thrust) and thrust force of a synchronous motor will be analyzed. linear according to the frequency selection from $5-50 \mathrm{~Hz}$, to drive the electric train locomotive.
\end{abstract}

Keywords: synchronous motor, permanent magnet, electric rail train

\begin{abstract}
ABSTRAK
Kereta listrik yang terbaru saat ini, telah mulai banyak digunakan motor sinkron linier dengan magnet permanen sebagai penggerak lokomotif. Magnet permanen ini mempunyai fungsi yang sama dengan motor sinkron konvensional yaitu untuk menghasilkan medan magnet sehingga motor dapat bergerak secara linier.Motor sinkron linier ini tidak memiliki gigi (gear) dan poros sumbu, namun gerakan mekanis motor linier ini sinkron dengan medan magnet berjalan. Medan magnet berjalan ini dihasilkan oleh belitan fasa tiga dan susunan kutub magnet $U, S, U, S$. . Karena motor itu sinkron linier merupakan motor berkecepatan tinggi, kecepatan mekanisnya sama dengan besarnya kecepatan medan magnet berjalan. Sehingga motor ini mampu menghasilkan daya dorong yang besar dibandingkan dengan penggunaan motor konvesional (motor DC dan motor induksi) untuk menggerakkan kereta rel listrik (KRL). Jika pada motor sinkron konvensional menggunakan frekuensi $50 \mathrm{~Hz}$, maka pada motor sinkron linier dengan kecepatan tinggi menggunakan frekuensi dari 5-50 Hz dalam mengubah kecepatannya dan pada penelitian ini akan dianalisa efisiensi, daya elekromagnetik (daya dorong) dan gaya dorong suatu motor sinkron linier sesuai pemilihan frekuensi dari 5-50 Hz, untuk menggerakan lokomotif kereta listrik.
\end{abstract}

Kata kunci: motor sinkron, magnet permanen, kereta rel listrik 


\section{PENDAHULUAN}

Sering bertumbuh pesatnya penduduk di daerah perkotaan menyebabkan mobilitas menjadi tinggi pula sehingga menuntut penyediaan alat transportasi yang bisa mengatasi masalah daya angkut dalam jumlah besar, penyediaan jalur bebas hambatan dari kemacetan dan dapat bergerak dengan cepat. Hal ini mendorong Industri Transportasi untuk menjawab permasalahan tersebut salah satunya menggunakan kereta rel listrik (KRL).

Kereta listrik yang banyak digunakan oleh Perusahaan Jawatan Kereta Api (PJKA) di Indonesia merupakan kereta listrik dengan menggunakan motor DC sebagai penggerak lokomotif. Hal tersebut tidak terlepas dari belum berkembangnya teknologi pada waktu itu sehingga penggunaan motor DC lebih banyak dipergunakan hingga sekarang. Namun dengan perkembangan teknolgi yang pesat, penggunaan motor AC sebagai penggerak lokomotif bisa diterapkan pada sistem kereta rel listrik di Indonesia seperti yang telah banyak digunakan oleh negara-negara maju di dunia.

Motor AC yang digunakan merupakan motor sinkron linier, motor sinkron ini memiliki tingkat kerja dan kecepatan yang baik. Dalam penelitian ini akan dibahas gaya dorong, daya elekromagnetik, dan kecepatan medan magnet berjalan sesuai dengan pemilihan frekuensi dan efisiensi yang dihasilkan motor AC (motor sinkron linier).

\section{METODE/PERANCANGAN PENELITIAN}

\subsection{Motor Sinkron Linier}

Motor sinkron linier merupakan motor listrik yang tidak berputar sehingga torsi (momen putar) digantikan oleh gaya lurus yang dihasilkan oleh medan magnet berjalan, motor ini dapat bergerak secara linier tanpa ada perantara perpindahan ggl, jadi gerak mekanis motor ini sinkron dengan besar medan magnet berjalan artinya kecepatan mekanisnya sama dengan kecepatan medan magnet berjalan lalu menjadi gaya dorong yang bisa untuk menggerakkan suatu benda.

Pada motor sinkron tiga fasa berputar dengan sistem eksitasi elektromagnet arus DC gaya dorong dihasilkan oleh dua macam komponen, yaitu: (1) Gaya gerak magnet (ggm) dan arus fluks magnet DC (komponen sinkron); atau (2) Gaya gerak magnet (ggm) dan reluktansi pada sumbu $d$ dan $q$ (komponen reluktansi).

Pada dasarnya motor linier dibagi dalam dua jenis, yaitu:

(1) Motor sinkron dengan inti besi

(2) Motor sinkron dengan inti udara

Sebagaimana halnya dengan mesin-mesin listrik, sebuah rotor mesin sinkron yang berputar pada dasarnya juga dipotong, lalu dibentangkan secara mendatar. Bila rotor mesin sinkron yang berbentuk silinder dipotong pada titik $\mathrm{P}$, lalu dibentangkan secara horizontal sehingga merupakan pelat datar. Arus-arus induksi dalam pelat ini bereaksi dengan fluks dari stator dan timbul suatu gaya F yang akan menyebabkan pelat ini bergerak menurut arah gaya $F$ itu. Dalam praktiknya, hal ini sulit untuk dilakukan pada sebuah mesin sinkron, sebab baik rotor maupun statornya memiliki belitan dan untuk membuat belitan sepanjang lokomotif akan membutuhkan biaya yang sangat mahal. Kesulitan mengenai konstruksi tersebut dapat diatasi dengan membuat suatu mesin homopolar, sehingga baik belitan arus searah maupun belitan arus bolak-balik yang dipasang pada stator tidak akan menjadi masalah dalam pemasangannya.

Sedangkan motor linier dengan inti udara merupakan mesin yang istimewa karena berintikan udara. Motor linier berinti besi memiliki kelemahan yaitu banyak menggunakan bahan feromagnetik yang perlu dipasang sepanjang lokomotif kereta, sehingga bobot dari bahan feromagnettik yang diperlukan stator menjadi berat untuk kereta. Belitan medan dan kutub dipasang pada kereta yang berfungsi sebagai rotor yang bergerak secara linier. Karena kutub tidak berinti besi, melainkan udara 


\section{Energi dan Kelistrikan: Jurnal Ilmiah}

Vol. 11, No. 2, Juli - Desember 2019, P-ISSN 1979-0783, E-ISSN 2655-5042

https://doi.org/10.33322/energi.v11i2.489

maka diperlukan arus medan yang besar sekali untuk mendapatkan kuat medan yang mencukupi. Hal tersebut hanya akan tercapai bila belitan kutub dibuat dari bahan super produktif, sehingga hal ini memungkinkan kereta memiliki daya dorong yang tinggi. Sedangkan kerugiannya yaitu belitan stator harus dipasang sepanjang jalan kereta tentu saja membutuhkan biaya yang tidak sedikit.

Kereta futuristic atau kereta listrik yang dibayangkan akan dipakai dikemudian hari tidak akan menggunakan roda lagi kalaupun ada rodanya, roda ini tidak berfungsi sebagai pendorong hanya sekedar berfungsi sebagai pemukul dan pembatas agar kereta tidak keluar dari rel kereta. Kereta diangkat atau mendapat suautu 'levitasi' yang berlandaskan suatu kuat medan yang besar. Sehingga kereta tersebut seolah-olah bertumpu pada suatu "bantal magnet" meluncur pada ada gesekan dengan tanah.

Untuk eksitasi pada motor sinkron linier menggunakan magnet permanen (MP), magnet permanen dapat dibagi menjadi dua jenis, yaitu:

- MP MSL dengan arus input yang bentuk gelombangnya sinusoidal dan menghasilkan medan magnet berjalan

- MP MSL dengan arus input yang bentuk gelombangnya rectangular atau trapezoidal dan juga menghasilkan medan magnet berjalan.

Untuk sistem eksitasi electromagnet arus DC diterapkan dalam motor sinkron berputar, sedangkan sistem eksitasi MP diterapkan dalam MSL. Belitan jangkar menghasilkan medan magnet berjalan dalam membangkitkan daya dorong yang dilakukan bersama fluks magnet yang dihasilkan dari kutub magnet atau reaktansi pada sumbu $d$ dan $q$ yang dihasilkan oleh plat inti besi feromagnetik.

Pada kasus operasi motor sinkron linier dengan prinsip medan magnet berjalan yaitu kecepatan pada bagian yang bergerak (v) sama dengan kecepatan sinkron (Vs) medan magnet berjalan yang nilainya tergantung pada frekuensi input dan pole pitch sehingga menghasilkan suau gaya dorong. Dibawah ini berlaku persamaan untuk kecepatan linier (sinkron) pada motor sinkron linier (MSL), yaitu:

$$
v=\frac{\omega \times \tau}{\pi}=2 \times \tau \times f
$$

Keterangan:

$\mathrm{V}=\mathrm{Vs}=$ kecepatan linier (meter/detik)

$\mathrm{f}=$ frekuensi $(\mathrm{Hz})$

$\tau=$ pole pitch (meter)

Magnet Permanen (MP) pada motor sinkron linier dapat dibagi berdasarkan karakteristik fisik, yaitu:

- Inti besi atau inti udara

- Berslot atau tidak berslot

- Bentuk datar atau silinder

- Sisi tunggal atau sisi ganda

- Fluks transversal atau fluks longitudinal

- Magnet permanen di permukaan slot atau magnet permanen tertanam pada slot

Motor sinkron linier dapat beroperasi dengan prinsip medan magnet berjalan, sistem eksitasinya dapat terjadi melalui:

(1) MP di dalam rel reaksi (rel reaksi aktif)

(2) MP di dalam jangkar (rel reaksi pasif)

(3) Sistem eksitasi superkonduktor

(4) Motor reluktansi variabel.

68 | Energi dan Kelistrikan: Jurnal Ilmiah 
Pada dasarnya fluks eksitasi dihasilkan oleh elektromagnet dan inti feromagnetik, maka dengan menggantikan electromagnet ini dengan penghantar elektromagnet superkonduktor tanpa inti, sistem eksitasi MSL akan memperoleh kekuatan yang lebih besar karena intensitas fluks magnet yang dihasilkan lebih besar dari pada intensitas fluks magnet pada inti besi yang terbaik, sehingga tidak dibutuhkan lagi inti besi feromagnetik atau dengan kata lain motor ini memiliki sistem eksitasi inti udara.

\section{HASIL DAN PEMBAHASAN}

Pada kereta listrik di Indonesia bekerja pada tegangan DC 1500 volt sedangkan pada tegangan kerja kereta listrik di Jerman dan Swiss, yaitu pada tegangan AC 2,6 kV dan 10kV pangkat 16, oleh karena itu penulis menerapkan tegangan kerja AC pada mesin 1000-10000 volt. Pemilihan frekuensi $5-50 \mathrm{~Hz}$ karena semakin besar frekuensinya maka akan semakin besar pula kecepatan yang dihasilkan, sehingga besarnya frekuensi dibatasi dengan nilai tersebut. Medan magnet berjalan yang terjadi dalam menghasilkan kecepatan yang selanjutnya, menjadi gaya dorong sehingga mampu meggerakkan kereta listrik, dipengaruhi langsung oleh frekuensi input. Tidak seperti pada motor sinkron berputar yang memang memerlukan frekuensi input yang pada umumnya sama dengan frekuensi sistem karea frekuensi pada mesin sinkron berputar menentukan besar nilai kecepatan putar angular dari rotor, lalu perputaran ini menghasilkan torsi (momen putar) yang selanjutnya diatur melalui perpindahan gigi (gear) untuk mendapatkan kecepatan dari terakhir dikonversikan lagi menjadi gaya dorong.

Perhitungan pada bab ini merupakan asumsi yang dilakukan dengan penyesuaian keadaan terhadap parameter yang akan dihitung. Hal ini karena MSL merupakan mesin aplikasi baru sehingga penggunaannya masih terbatas. Selain itu penulis tidak melakukan studi kasus pada lokasi pengujian motor sinkron linier, perusahaan MSL ataupun kereta listrik yang telah menggunakan MSL sebagai penggeraknya karena di Indonesia sendiri belum ada satupun alat aplikasi yang sudah menerapkan MSL, sehingga data yang didapatkan penulis baik melalui pembacaan dari literature maupun browsing melalui internet masih sangat terbatas.

Adapun perhitunga pada bab ini akan ditampilkan suatu penerapan perhitungan, solusi cara pemecahan masalah, jawaban yang tercantum dalam tabel dan gambar grafik hubungan antara parameter yang telah dihitung dan yang akan dibandingkan.

Suatu kereta listrik tanpa roda dengan penggerak motor sinkron linier fasa tiga dengan karakteristiik fisik datar, sisi tunggal, magnet permanen pada permukaan, berdaya $500 \mathrm{~kW}$ hubungan bintang dan faktor daya $=0,85$.

\section{KESIMPULAN DAN SARAN}

Dari hasil pembahasan diatas dapat disimpulkan bahwa:

1) Unjuk kerja dari motor sinkron linier (MSL) dipengaruhi oleh karakteristik fisik (konstruksi penyusunan magnet permanen) dan gaya dorong yang dihasilkan oleh motor sinkron linier (MSL) dipengaruhi oleh dua macam faktor, yaitu:

- Faktor internal besarnya tergantung dari fluks magnet dan medan magnet berjalan

- Faktor eksternal besarnya tergantung dari masa (lokomotif dan gerbong), percepatan dan perlambatan kereta, serta koefisien gesek.

2) Besarnya kecepatan sinkron yang dihasilkan oleh medan magnet berjalan sama dengan kecepatan mekanis (kecepatan linier) dari benda yang bergerak. Misalnya bila suau kereta dengan MSL lalu menghasilkan medan magnet berjalan dengan kecepatan $50 \mathrm{~m} /$ detik 
maka kecepatan kereta api bergerak juga dengan kecepatan $50 \mathrm{~m} /$ detik atau sekitar 180 $\mathrm{km} / \mathrm{jam}$.

3) Besar nilai medan magnet berjalan dalam menghasilkan kecepatan linier ditentukan oleh dua faktor, yaitu: Frekuensi (f) dan Pole pitch $(\tau)$.

4) Pada perhitungan besaran listrik pada MSL dapat diketahui bahwa dengan menggunakan tegangan sumber dengan nilai yang besar maka didapatkan efisiensi mesin yang tinggi.

5) Pada perhitungan daya dorong dan gaya dorong pada MSL diketahui bahwa frekuensi akan memengaruhi besarnya gaya dorong. Semakin besar frekuensi maka akan semakin besar kecepatan namun gaya dorong yang dihasilkan semakin berkurang.

6) Pada perhitungan gaya dorong dan daya dorong pada MSL diketahui bahwa untuk mendapatkan gaya dorong yang besar maka diperlukan daya elektromagnetik (daya dorong) yang besar, untuk itu rugi-rugi belitan jangkar juga harus kecil. Maka untuk mendapatkan rugi belitan jangkar yang kecil, tegangan sumber dinaikkan agar arus jangkarnya yang kecil dengan asumsi nilai daya input tetap.

7) Motor sinkron linier (MSL) sebagai mesin aplikasi terbaru memiliki kinerja yang baik, namun masih memiliki kelemahan karena penggunaannya hingga sekarang masih terbatas pada alat transportasi dan tentu saja memiliki harga yang masih mahal. Namun untuk penerapannya di Indonesia sendiri sangat memungkinkan karena selain untuk memenuhi tuntutan akan tingginya mobilitas penduduk terutama di daerah perkotaan, juga sebagai usaha peremajaan alat transportasi yang ada di Indonesia saat ini.

\section{UCAPAN TERIMA KASIH}

Penulis mengucapkan terima kasih kepada Ketua STT-PLN, kepala LPPM dan kepada Kepala Departemen Elektro yang telah memberi dukungan yang membantu pelaksanaan penelitian dan atau penulisan artikel ini.

\section{DAFTAR PUSTAKA}

[1] A.E.Fitzgerald, Charles Kingsley.jr, Stephen D. Umas, Mesin-Mesin Listrik Edisi ke-4. Jakarta : Erlangga, 1997.

[2] A.E.Fitzgerald dan Jr, Kingsley, Electrical Machinery 6th . New York : Mc Graw - Hill, 2003.

[3] B. L. Theraja. Electrical Technology 17th revised edition . New Delhi: S. Chand \& Company Ltd,1978

[4] Bueche F. J, SERI BUKU SCHAUM . Jakarta : Erlangga, 1999.

[5] Boldea. Ion, Synchronous Generators . London : Taylor \& Francis Group, 2006.

[6] J.B. Gupta, Electric Machinery and Electric Traction . New Delhi, 1976.

[7] Jacek F. Giersd dan Zbigniew J. Piech, Liniear Synchronous Motors on Transportation and Automation Systems. New York : CRC Press, 2000.

[8] Kadir. Abdul, Mesin Induksi. Jakarta : Djambatan, 1986.

[9] Kadir. Abdul, Mesin Sinkron. Jakarta : Djambatan, 1992.

[10] Zuhal. Dasar Teknik Tenaga Listrik Dan Elektronika Daya . Jakarta : Gramedia Pustaka Utama, 1995. 